Article

\title{
Poly(tris(4-carbazoyl-9-ylphenyl)amine)/Three Poly(3,4-ethylenedioxythiophene) Derivatives in Complementary High-Contrast Electrochromic Devices
}

\author{
Chung-Wen Kuo ${ }^{1}$, Jeng-Kuei Chang ${ }^{2}$, Yuan-Chung Lin ${ }^{3}$, Tzi-Yi Wu ${ }^{4, *} \mathbb{C}$, Po-Ying Lee ${ }^{1}$ \\ and Tsung-Han Ho ${ }^{1}$ \\ 1 Department of Chemical and Materials Engineering, National Kaohsiung University of Applied Sciences, \\ Kaohsiung 80778, Taiwan; welly@cc.kuas.edu.tw (C.-W.K.); k40017105@gcloud.csu.edu.tw (P.-Y.L.); \\ thho@cc.kuas.edu.tw (T.-H.H.) \\ 2 Institute of Materials Science and Engineering, National Central University, Taoyuan 32001, Taiwan; \\ jkchang@ncu.edu.tw \\ 3 Institute of Environmental Engineering, National Sun Yat-Sen University, Kaohsiung 80424, Taiwan; \\ yclin@faculty.nsysu.edu.tw \\ 4 Department of Chemical Engineering and Materials Engineering, National Yunlin University of Science \\ and Technology, Yunlin 64002, Taiwan \\ * Correspondence: wuty@gemail.yuntech.edu.tw; Tel.: +886-5-534-2601 (ext. 4626)
}

Received: 21 September 2017; Accepted: 17 October 2017; Published: 23 October 2017

\begin{abstract}
A carbazole-based polymer (poly(tris(4-carbazoyl-9-ylphenyl)amine) (PtCz)) is electrosynthesized on an indium tin oxide (ITO) electrode. $\mathrm{PtCz}$ film displays light yellow at $0.0 \mathrm{~V}$, earthy yellow at $1.3 \mathrm{~V}$, grey at $1.5 \mathrm{~V}$, and dark grey at $1.8 \mathrm{~V}$ in $0.2 \mathrm{M} \mathrm{LiClO}_{4} / \mathrm{ACN} / \mathrm{DCM}$ (ACN/DCM $=1: 3$, by volume) solution. The $\Delta T$ and coloration efficiency $(\eta)$ of PtCz film are $30.5 \%$ and $54.8 \mathrm{~cm}^{2} \cdot \mathrm{C}^{-1}$, respectively, in a solution state. Three dual-type electrochromic devices (ECDs) are fabricated using the $\mathrm{PtC} z$ as the anodic layer, poly(3,4-ethylenedioxythiophene) (PEDOT), poly(3,3-dimethyl-3,4-dihydro-thieno[3,4-b][1,4]dioxepine) (PProDOT-Me 2 ), and poly(3,4(2,2-diethylpropylenedioxy)thiophene) (PProDOT-Et ${ }_{2}$ ) as the cathodic layers. PtCz/PProDOT-Me 2 ECD shows high $\Delta T_{\max }(36 \%)$, high $\eta_{\max }\left(343.4 \mathrm{~cm}^{2} \cdot \mathrm{C}^{-1}\right)$, and fast switching speed $(0.2 \mathrm{~s})$ at $572 \mathrm{~nm}$.

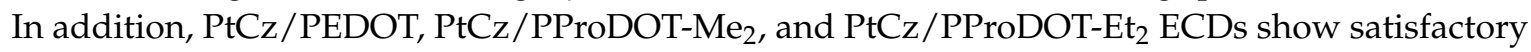
open circuit memory and long-term stability.
\end{abstract}

Keywords: electrochemical polymerization; optical contrast; electrochromic switching; coloration efficiency; electrochromic device

\section{Introduction}

$\pi$-conjugated polymers (CPs) and oligomers have attracted a great deal of interest due to their suitability for potential applications in supercapacitors [1,2], catalysts [3-5], actuators [6], polymer light-emitting diodes [7-9], electrochromic devices (ECDs) [10-12], polymer solar cells [13], and sensors [14-16]. The most commonly studied classes of CPs are poly(phenylene vinylene)s (PPV) [17], polycarbazoles (PCz) [18,19], polythiophenes (PT) [20], polypyrroles (PPy) [21], poly(3,4-ethylenedioxythiophene) (PEDOT) [22], and polyanilines (PANI) [23]. Cz-based polymers have been widely used as hole transporting and host materials in optoelectronic devices due to the nitrogen atom of $\mathrm{Cz}$ ring shows good hole transporting ability, high thermal stability, and ease of formation of radical cations and dications [24]. Polythiophenes and polypyrroles have been extensively used as electrochromic materials due to the fact that they can be easily 
synthesized electrochemically or chemically with a wide range of electrochromic properties available through alkyl, alkoxy, and phenyl substitution on polythiophenes and polypyrroles. PEDOT and its derivatives poly(3,3-dimethyl-3,4-dihydro-thieno[3,4-b][1,4]dioxepine) (PProDOT-Me 2 ) and poly(3,3-diethyl-3,4-dihydro-thieno[3,4-b][1,4]dioxepine) (PProDOT-Et ${ }_{2}$ ) were extensively investigated for many useful properties including low oxidation potential, electron-rich dioxy group, optical transparency in doped state, moderate band gap, and high stability $[25,26]$.

There have been no reports for the applications of poly(tris(4-carbazoyl-9-ylphenyl)amine) as anodic polymer in electrochromic devices. In the present study, a carbazole-based monomer (tris(4-carbazoyl-9-ylphenyl)amine, $\mathrm{tCz}$ ) was synthesized and its corresponding homopolymer (PtCz) was polymerized electrochemically. The spectroelectrochemistry, electrochromic photographs, optical contrast, and coloration efficiency of $\mathrm{PtCz}$ film in solution state were studied. Moreover, dualtype ECDs based on PtCz and PEDOT derivatives were fabricated, the electrochromic behaviors, open circuit memory, and long-term switching stability of $\mathrm{PtCz} / \mathrm{PEDOT}, \mathrm{PtCz} / \mathrm{PProDOT}-\mathrm{Me}_{2}$, and $\mathrm{PtC} z / \mathrm{PProDOT}_{-} \mathrm{Et}_{2}$ ECDs were also investigated.

\section{Materials and Methods}

\subsection{Materials}

All chemicals were purchased from Sigma-Aldrich, Tokyo Chemical Industry Co., Ltd. (TCI, Tokyo, Japan), Acros (Geel, Belgium), Alfa-Aesar (Ward Hill, MA, USA), and used as received. Tris(4-carbazoyl-9-ylphenyl)amine, 3,3-dimethyl-3,4-dihydro-thieno[3,4-b][1,4]dioxepine (ProDOT-Me 2 ) and 3,3-diethyl-3,4-dihydro-thieno[3,4-b][1,4]dioxepine (ProDOT-Et 2 ) were synthesized following previously published procedures $[27,28]$.

\subsection{Synthesis of Tris(4-carbazoyl-9-ylphenyl)amine ( $t C z)$}

Carbazole (70.22 mg, $0.42 \mathrm{mmol})$, tris(4-iodophenyl)amine ( $68.53 \mathrm{mg}, 0.11 \mathrm{mmol}), \mathrm{K}_{2} \mathrm{CO}_{3}(165.84 \mathrm{mg}$, $1.20 \mathrm{mmol})$, Cu bronze $(69.58 \mathrm{mg}, 1.095 \mathrm{mmol})$ and 18 -crown-6 $(8.72 \mathrm{mg}, 0.033 \mathrm{mmol})$ were stirred in $45 \mathrm{~mL}$ 1,2-dichlorobenzene for two days at $190{ }^{\circ} \mathrm{C}$. The crude product is vacuum distilled and the residue is purified by column chromatography using a mixture of hexane and dichloromethane (DCM) (2:1 by volume) as eluent. Yield: $41 \% .{ }^{1} \mathrm{H}-\mathrm{NMR}\left(700 \mathrm{MHz}, \mathrm{DMSO}-\mathrm{d}_{6}\right): \delta 8.26(\mathrm{~d}, 6 \mathrm{H}, \mathrm{Ar}-\mathrm{H}), 7.69(\mathrm{dd}$, 6H, Ar-H), 7.57 (dd, 6H, Ar-H), 7.50-7.46 (m, 12H, Ar-H), 7.32-7.30 (m, 6H, Ar-H). Elem. anal. calcd. for $\mathrm{C}_{54} \mathrm{H}_{36} \mathrm{~N}_{4}$ : C, $87.54 \% ; \mathrm{H}, 4.90 \%$; N, 7.56\%. Found: $\mathrm{C}, 87.32 \% ; \mathrm{H}, 4.82 \% ; \mathrm{N}, 7.57 \%$.

\subsection{Electrosynthesis of PtCz, PProDOT-Me $2_{2}$ and PProDOT-Et $t_{2}$ Films}

The electrosynthesis of PtCz film in an ACN/DCM (1:3, by volume) solution containing $0.2 \mathrm{M} \mathrm{LiClO}_{4}$ as a supporting electrolyte was carried out by scanning the potential between 0.0 and $1.8 \mathrm{~V}(\mathrm{vs} . \mathrm{Ag} / \mathrm{AgCl})$ potentiodynamically at $100 \mathrm{mV} \cdot \mathrm{s}^{-1}$ for 3 cycles. The electrochemically deposited $\mathrm{PtCz}$ film was rinsed with DI water for $5 \mathrm{~min}$ and then dried at $105^{\circ} \mathrm{C}$ for $3 \mathrm{~min}$. As shown in Table 1, the PEDOT, PProDOT- $\mathrm{Me}_{2}$, and PProDOT-Et ${ }_{2}$ films were deposited from $0.008 \mathrm{M}$ EDOT, $0.010 \mathrm{M}$ ProDOT-Me $\mathrm{M}_{2}$ and $0.017 \mathrm{M} \mathrm{ProDOT}^{-\mathrm{Et}_{2}}$ in a $0.2 \mathrm{M} \mathrm{LiClO}_{4}$ /acetonitrile (ACN) solution, respectively. Electrosynthesis of PEDOT, PProDOT-Me $\mathrm{M}_{2}$, and PProDOT-Et $t_{2}$ films were performed potentiostatically at $1.7 \mathrm{~V}$ (vs. $\mathrm{Ag} / \mathrm{AgCl}$ ) for $50 \mathrm{mC}$. Polymer thicknesses at the electrode surface obtained from an Alpha-Step profilometer (KLA Tencor D-120, CA, USA) were about 200-300 nm.

Table 1. Feed species of cathodic polymer electrodes (a)-(c).

\begin{tabular}{cccc}
\hline Electrodes & Cathodic Polymer & Feed Species & Deposition Amount of Cathode \\
\hline (a) & PEDOT & $8 \mathrm{mM}$ EDOT & $50 \mathrm{mC}$ \\
(b) & PProDOT-Me $_{2}$ & $10 \mathrm{mM}$ ProDOT-Me & $50 \mathrm{mC}$ \\
(c) & PProDOT-Et $_{2}$ & $17{\mathrm{mM} \mathrm{ProDOT}-\mathrm{Et}_{2}}^{2}$ & $50 \mathrm{mC}$ \\
\hline
\end{tabular}




\subsection{Electrochromic Characterization}

Electrochromic characterization of the polymer films and electrochromic devices were carried out using a CHI627D electrochemical analyzer (CH Instruments, Austin, TX, USA). Cyclic voltammetry (CV) studies were performed using in a three-component cell, which contained an ITO-coated glass plate (area: $1 \mathrm{~cm} \times 1.5 \mathrm{~cm}$ ) as the working electrode, a platinum wire as the counter electrode, and an $\mathrm{Ag} / \mathrm{AgCl}$ as the reference electrode. The in situ spectroelectrochemical spectra were recorded using an Agilent Cary 60 UV-Visible spectrophotometer (Varian Inc., Walnut Creek, CA, USA) in time course mode.

\subsection{Preparation of Electrochromic Electrolytes}

The polymer electrolytes of the ECDs were prepared using the solution-cast method. To prepare the solution, poly(methyl methacrylate) (PMMA), propylene carbonate (PC), and $\mathrm{LiClO}_{4}$ were dissolved in acetone, and the mixture was stirred magnetically at room temperature for $36 \mathrm{~h}$. The polymer electrolytes were prepared using PMMA:PC: $\mathrm{LiClO}_{4}$ in a weight ratio of 33:53:14. The final mixture was cast on glass petri dishes. After evaporating the solvent at room temperature for $2 \mathrm{~h}$, the samples were vacuum-dried at $80^{\circ} \mathrm{C}$ for $24 \mathrm{~h}$ to remove the remaining solvent completely. Finally, the self-standing polymer electrolytes were obtained. The ECDs were fabricated by sandwiching the polymer electrolytes between two electrodes to perform the electrochromic measurements.

\subsection{Fabrication of the ECDs}

The ECDs were constructed using two complementary polymer layers, $\mathrm{PtCz}$ as the anodically coloring layer, PEDOT, PProDOT-Me ${ }_{2}$, or PProDOT-Et $t_{2}$ as the cathodically coloring layer. PtCz, PEDOT, PProDOT-Me ${ }_{2}$, and PProDOT-Et $t_{2}$ films were deposited on ITO substrates (active area: $1 \mathrm{~cm} \times 1.5 \mathrm{~cm}$ ). The ECDs were fabricated by arranging the oxidized and reduced films to face each other, and they were separated by an electrolyte. The fabrication procedures of ECDs are shown in Figure 1.

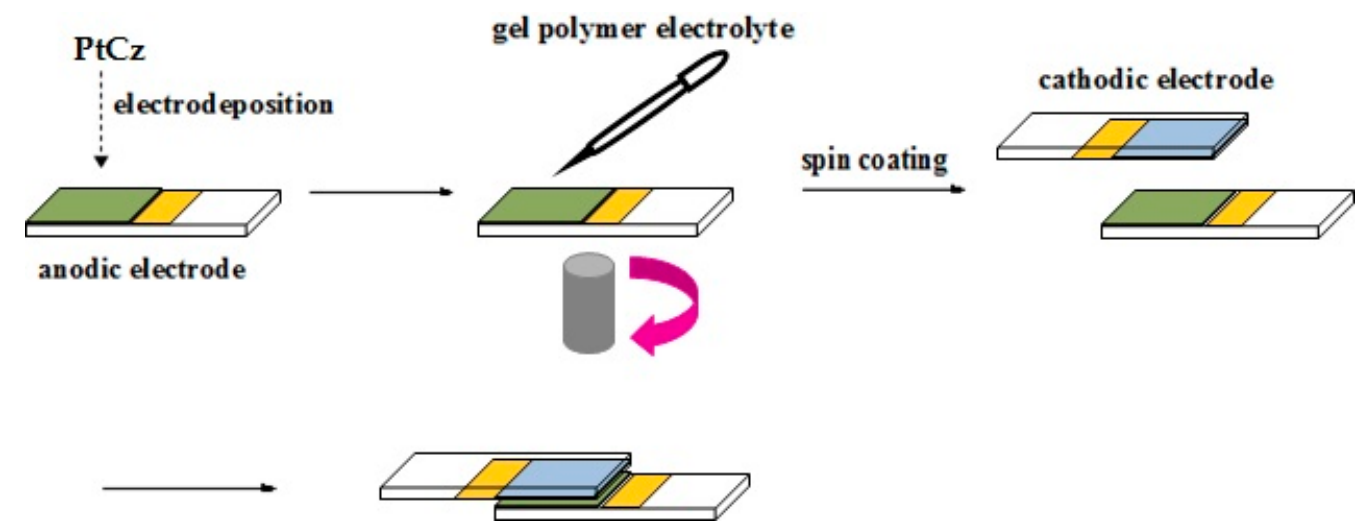

Figure 1. The fabrication procedures of electrochromic devices (ECDs).

\section{Results and Discussion}

\subsection{Electrochemistry of $t C z$ and Its Electrochemical Polymerization}

The electrosynthesis of $\mathrm{PtCz}$ film was implemented using CV with a scan rate of $100 \mathrm{mV} \cdot \mathrm{s}^{-1}$. The electropolymerization scheme and mechanism of PtCz are shown in Figure 2 [29]. The successive cyclic voltammograms of $0.002 \mathrm{M}$ neat $\mathrm{tC} z$ taken in an $\mathrm{ACN} / \mathrm{DCM}(1: 3$, by volume) solution containing $0.2 \mathrm{M} \mathrm{LiClO}_{4}$ as a supporting electrolyte at a scanning rate of $100 \mathrm{mV} \cdot \mathrm{s}^{-1}$ are shown in Figure 3 . For the first scan of cyclic voltammogram, the onset potential of $\mathrm{tCz}$ is $0.86 \mathrm{~V} \mathrm{vs.} \mathrm{Ag} / \mathrm{AgCl}$, two oxidation peaks located at 0.95 and $1.18 \mathrm{~V}$ indicate the polaron and bipolaron formation of $\mathrm{tC} z$, the reduction peaks of $\mathrm{tCz}$ locate at 1.1 and $0.7 \mathrm{~V}$. The increase in the oxidation and reduction curves wave current 
densities indicates that the amount of polymer deposited on the ITO working electrode increases with increasing cycles. The polymerization of $\mathrm{tCz}$ shows two quasi-reversible oxidation and reduction processes in Figure 3.

(a)

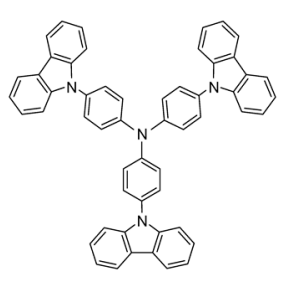

electrochemical polymerization

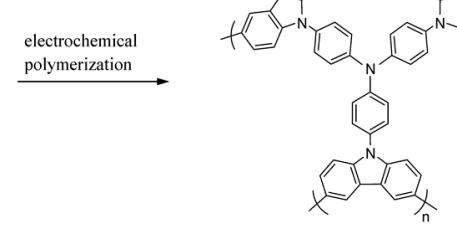

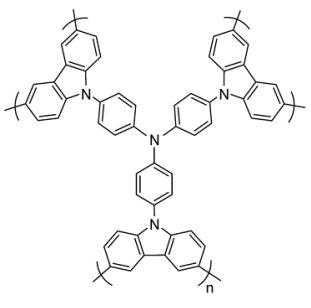

(b)

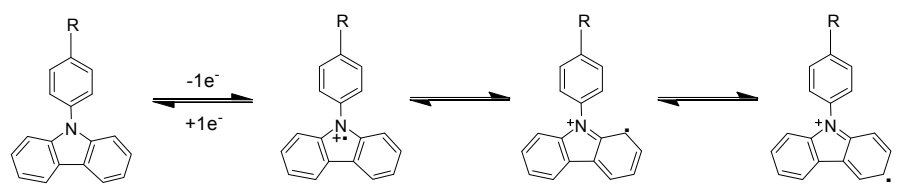

$\mathrm{R}=\mathrm{N}(\mathrm{PhCz})_{2}$

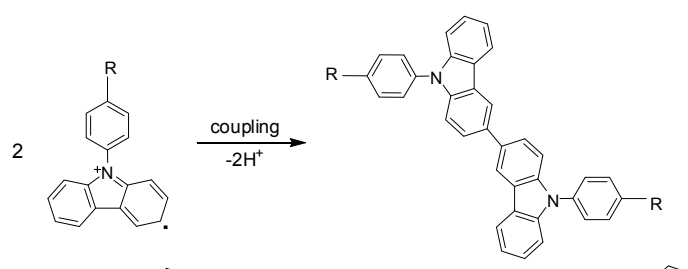

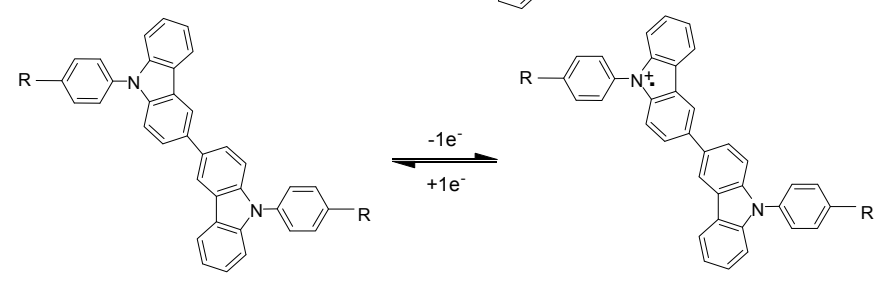
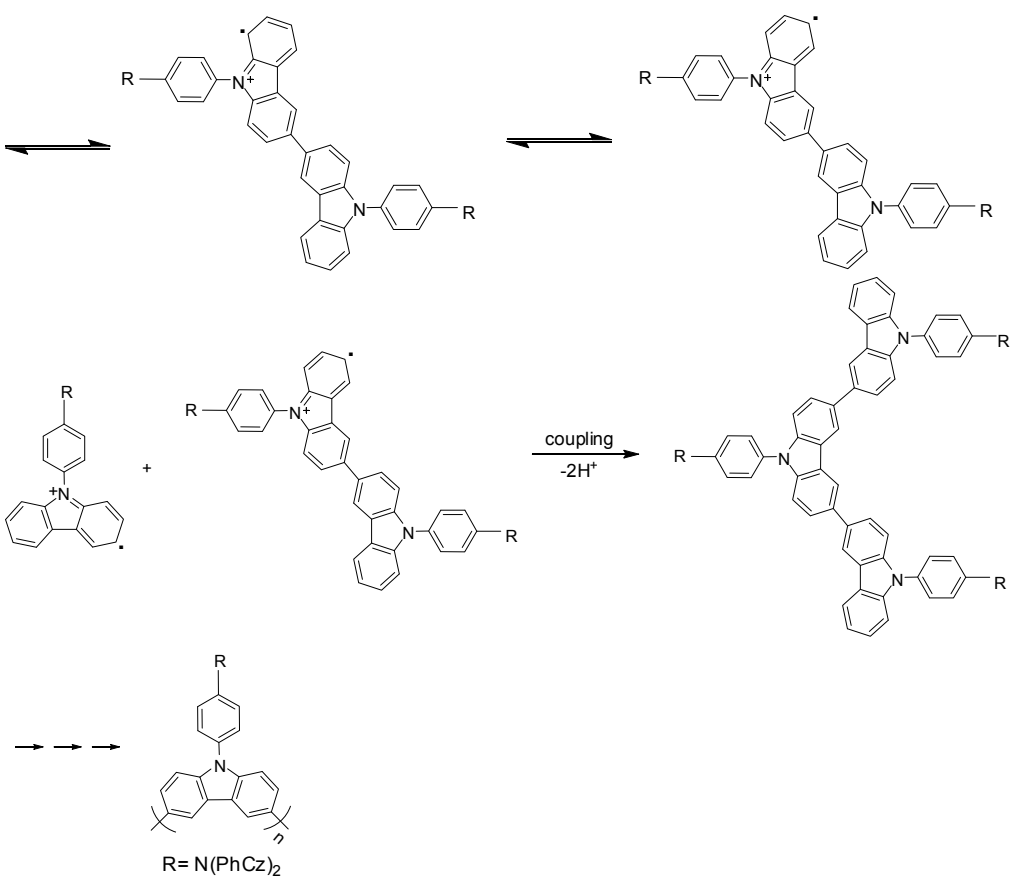

Figure 2. (a) The electrochemical polymerization scheme of the carbazole-based polymer (poly(tris(4carbazoyl-9-ylphenyl)amine) (PtCz)); (b) the electropolymerization mechanism of PtCz. 


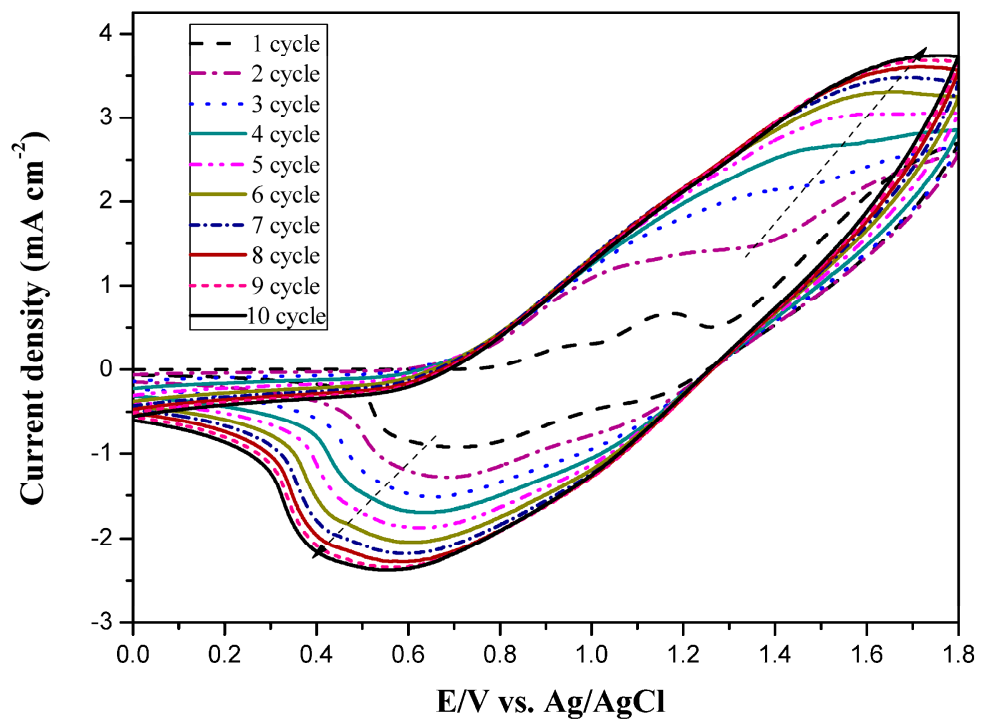

Figure 3. Electrochemical synthesis of $\mathrm{PtCz}$ in acetonitrile $(\mathrm{ACN}) /$ dichloromethane (DCM) (1:3, by volume) solution at $100 \mathrm{mV} \cdot \mathrm{s}^{-1}$ on indium tin oxide (ITO) working electrode.

\subsection{Electrochemical Behavior of PtCz Films}

The as-prepared $\mathrm{PtC} z$ film was swept between 0.0 to $1.8 \mathrm{~V}$ at various scan rates between 10 and $200 \mathrm{mV} \cdot \mathrm{s}^{-1}$ in $0.2 \mathrm{M} \mathrm{LiClO}_{4} / \mathrm{ACN} / \mathrm{DCM}$ solution. As shown in Figure 4, the electrochemical behavior of the PtCz film shows a single well-defined redox process, the anodic and cathodic peak current densities are proportional to the scan rates, implying that $\mathrm{PtCz}$ film is electroactive and adheres well to the electrode, and the electrochemical processes of $\mathrm{PtCz}$ film are reversible and not dominated by diffusion effects [30].

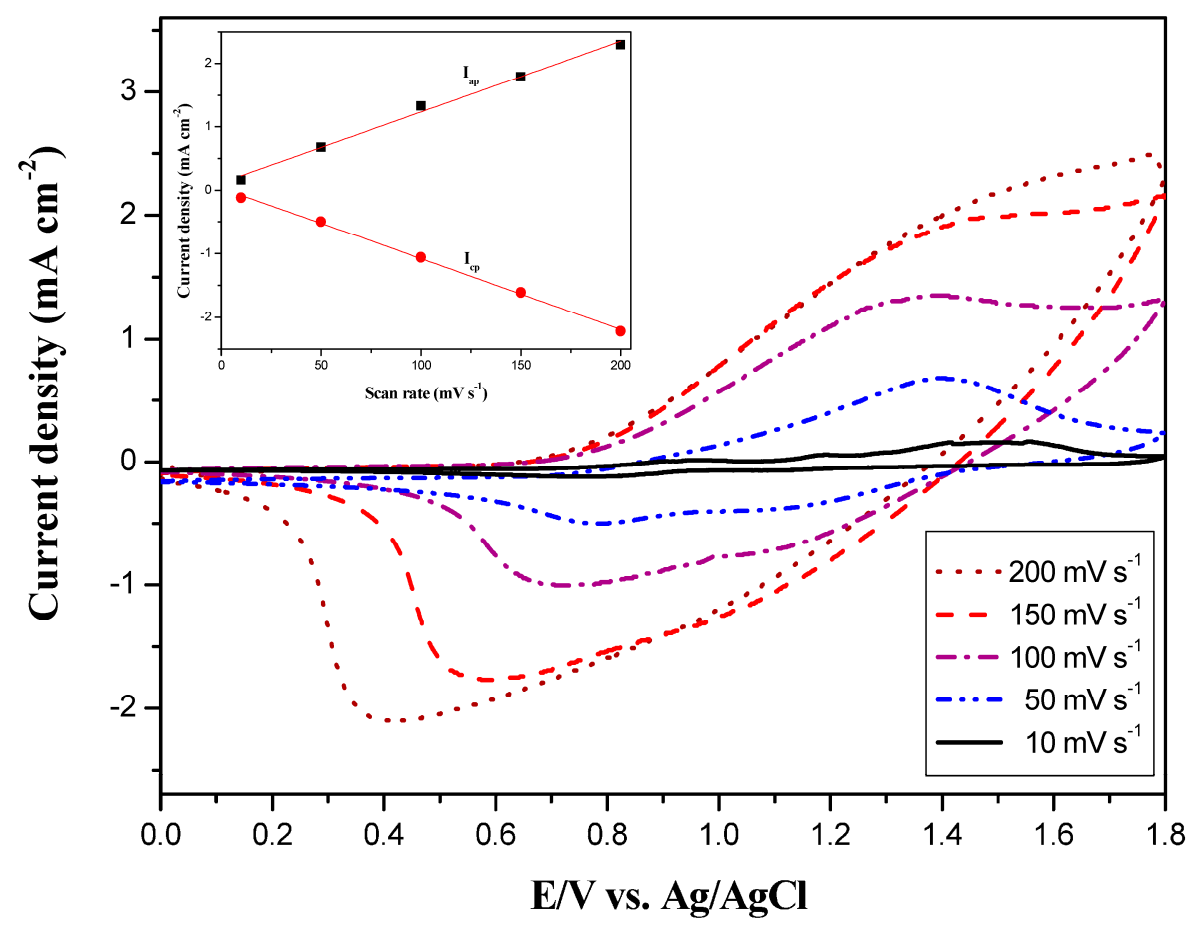

Figure 4. Cyclic voltammetry $(\mathrm{CV})$ curves of the $\mathrm{PtCz}$ film-coated ITO working electrode at different scan rates between 10 and $200 \mathrm{mV} \cdot \mathrm{s}^{-1}$ in $0.2 \mathrm{M} \mathrm{LiClO}_{4} / \mathrm{ACN} / \mathrm{DCM}$ solution. Inset: Scan rate dependence of the $\mathrm{PtCz}$ anodic and cathodic peak current densities, respectively. 


\subsection{Spectroelectrochemistry of PtCz and PProDOT-Me $e_{2}$ Films}

Spectroelectrochemistry can be used to analyze the changes in the absorption spectra of ECDs at various potentials [31]. Optoelectrochemical spectra of $\mathrm{PtCz}$ and PProDOT-Me $\mathrm{e}_{2}$ films are shown in Figure 5. The PtCz film shows a $\pi-\pi^{*}$ transition peak at around $360 \mathrm{~nm}$ at $0.0 \mathrm{~V}$, and it is light yellow in undoped state. Upon stepwise oxidation, the peak intensity at $360 \mathrm{~nm}$ diminishes gradually and new absorption bands at around $800 \mathrm{~nm}$ emerge, the $\mathrm{PtC}$ film displays earthy yellow at $1.3 \mathrm{~V}$, grey at $1.5 \mathrm{~V}$, and dark grey at $1.8 \mathrm{~V}$. On the other hand, the PProDOT-Me $\mathrm{e}_{2}$ film shows two significant peaks at 570 and $625 \mathrm{~nm}$ at $-1.5 \mathrm{~V}$ and presents dark blue in its neutral state. Upon oxidation progressively, the peak intensity at 570 and $625 \mathrm{~nm}$ diminish gradually and new absorption bands at more than $1000 \mathrm{~nm}$ emerge, the PProDOT-Me 2 film displays grey at $-0.8 \mathrm{~V}$ and light blue at $-1.5 \mathrm{~V}$. The colorimetric values $\left(L^{*}, a^{*}\right.$, and $\left.b^{*}\right)$, CIE chromaticity values $(x, y)$, and CIE chromaticity diagrams of the PtCz and PProDOT-Me $\mathrm{M}_{2}$ films at various potentials were shown in Table 2.
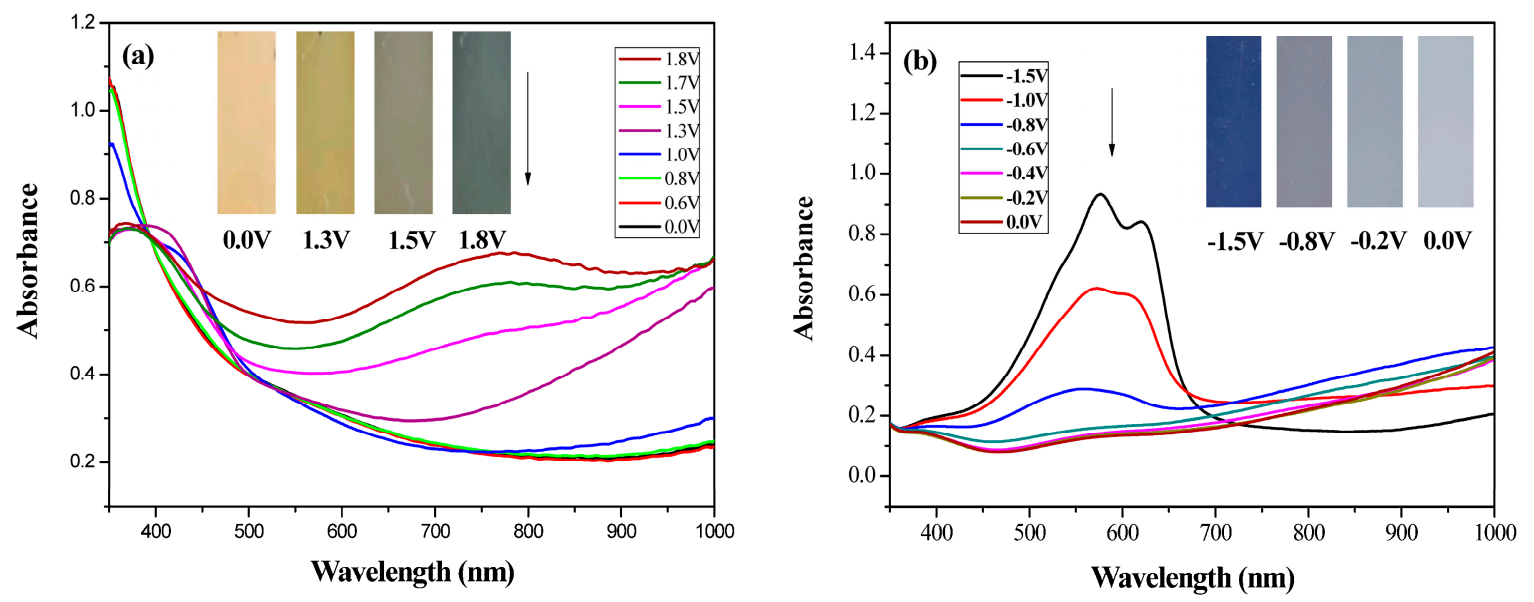

Figure 5. UV-Visible spectra of (a) PtCz and (b) PProDOT-Me $\mathrm{P}_{2}$ on ITO in an ACN/DCM (1:3, by volume) solution containing $0.2 \mathrm{M} \mathrm{LiClO}_{4}$.

Table 2. Colorimetric values $\left(L^{*}, a^{*}\right.$, and $\left.b^{*}\right)$, CIE chromaticity values $(x, y)$, and CIE chromaticity diagrams of the $\mathrm{PtC} z$ and PProDOT-Me $\mathrm{Me}_{2}$ at various applied potentials.

\begin{tabular}{|c|c|c|c|c|c|c|c|}
\hline Electrodes & Potential (V) & $L^{*}$ & $a^{*}$ & $b^{*}$ & $x$ & $y$ & Diagrams \\
\hline \multirow{6}{*}{$\mathrm{PtCz}$} & 0.0 & 73.95 & 5.59 & 15.85 & 0.4770 & 0.4159 & \\
\hline & 1.0 & 74.84 & 6.13 & 24.13 & 0.4864 & 0.4226 & \\
\hline & 1.3 & 73.46 & 3.02 & 21.02 & 0.4778 & 0.4248 & \\
\hline & 1.5 & 68.67 & -1.78 & 11.72 & 0.4588 & 0.4239 & \\
\hline & 1.7 & 64.66 & -3.54 & 6.65 & 0.4490 & 0.4215 & \\
\hline & 1.8 & 61.15 & -3.02 & 5.17 & 0.4482 & 0.4193 & \\
\hline \multirow{6}{*}{ PProDOT-Me } & -1.5 & 49.73 & 6.28 & -46.01 & 0.3710 & 0.3162 & \\
\hline & -1.0 & 60.60 & 5.54 & -31.57 & 0.4078 & 0.6232 & \\
\hline & -0.8 & 78.43 & 3.60 & -10.50 & 0.4411 & 0.3911 & \\
\hline & -0.4 & 88.43 & -2.94 & -5.89 & 0.4362 & 0.4050 & \\
\hline & -0.2 & 88.98 & -2.68 & -5.85 & 0.4368 & 0.4048 & \\
\hline & 0.0 & 89.37 & -2.56 & -5.18 & 0.4378 & 0.4053 & \\
\hline
\end{tabular}

\subsection{Electrochemical Switching of PtCz Film}

Double potential step techniques can be used to investigate the response time and stability of polymer films during consecutive scans [32]. The double potential step chronoamperometry coupled with spectrophotometer of $\mathrm{PtCz}$ film was performed by stepping potentials between 0.0 and $1.8 \mathrm{~V}$ with a residence time of $10 \mathrm{~s}$, and the transmittance-time profile of $\mathrm{PtCz}$ film is displayed in Figure 6. The coloration switching time $\left(\tau_{\mathrm{c}}\right)$ and bleaching switching time $\left(\tau_{\mathrm{b}}\right)$ were defined as the period 
required for achieving $90 \%$ of the desired response [33-36]. The $\tau_{\mathrm{c}}$ and $\tau_{\mathrm{b}}$ of $\mathrm{PtCz}$ film estimated at the third cycle at $760 \mathrm{~nm}$ are 5.5 and $5.0 \mathrm{~s}$, respectively. The optical contrast $(\Delta T \%)$ is an important property of electrochromic polymer films, which denotes as the transmittance difference between bleaching and coloring states of polymer films in solution state. The optical density $(\triangle \mathrm{OD})$ can be calculated using the following formula:

$$
\Delta \mathrm{OD}=\log \left(\frac{T_{\mathrm{ox}}}{T_{\text {red }}}\right)
$$

where $T_{\mathrm{ox}}$ is the transmittance of anodic material in coloration state and $T_{\text {red }}$ is the transmittance of anodic material in bleaching state.

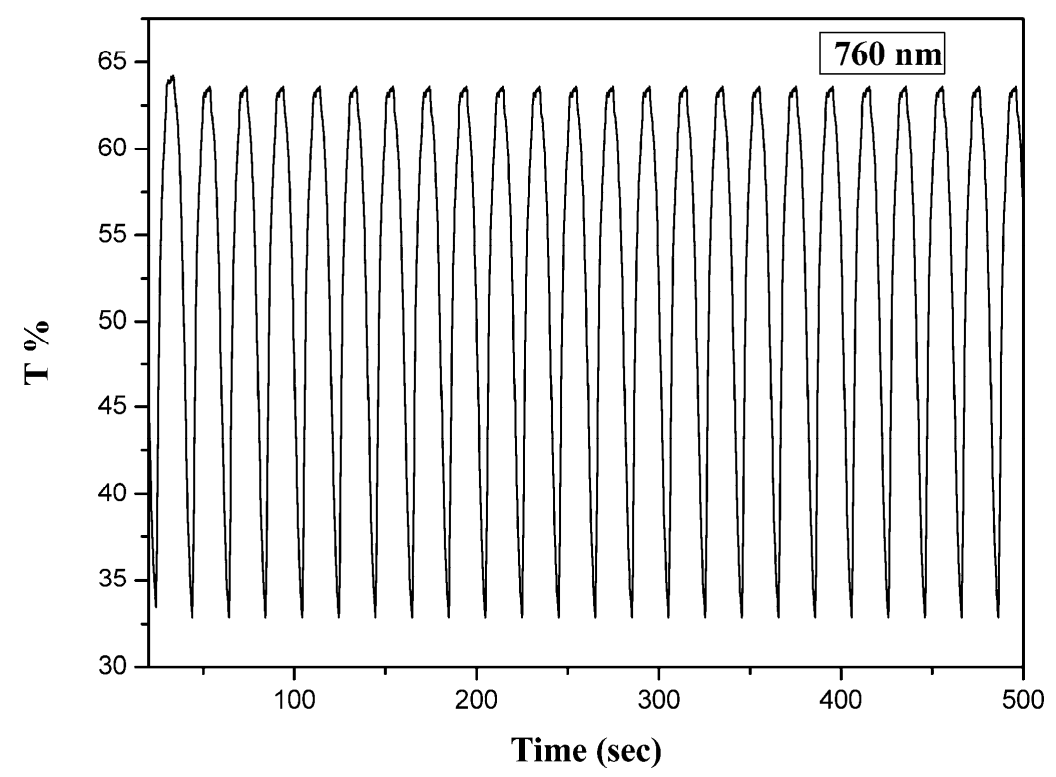

Figure 6. Optical contrast of PtCz electrode in an ACN/DCM (1:3, by volume) solution containing $0.2 \mathrm{M} \mathrm{LiClO}_{4}$ between $0.0 \mathrm{~V}$ and $1.8 \mathrm{~V}$ with a residence time of $10 \mathrm{~s}$.

As shown in Table 3, the $\Delta T_{\max }$ and $\Delta \mathrm{OD}$ values of PtCz film are $30.5 \%$ and -0.28 , respectively, at $760 \mathrm{~nm}$ in $0.2 \mathrm{M} \mathrm{LiClO}_{4} / \mathrm{ACN} / \mathrm{DCM}\left(\mathrm{ACN} / \mathrm{DCM}=1: 3\right.$, by volume) solution. The $\Delta T_{\max }$ of PtCz film is larger than those reported for poly( $9 H$-carbazol-9-ylpyrene) $\left(\Delta T_{\max }=29 \%\right.$ at $460 \mathrm{~nm}$ [37]) and poly(1,3-bis(carbazol-9-yl)benzene) $\left(\Delta T_{\max }=18.6 \%\right.$ at $1050 \mathrm{~nm}$ [38]) (Table 4). However, the $\Delta T$ of PtCz film is smaller than those reported for poly(ethyl-4-(3,6-di(thiophen-2-yl)-9H-carbazole-9-yl)-benzoate) $\left(\Delta T_{\max }=36 \%\right.$ at $1100 \mathrm{~nm}$ [39]), poly(2,5-bis(9-methyl-9H-carbazol-3-yl)-1,3,4-oxadiazole) $\left(\Delta T_{\max }=75 \%\right.$ at $660 \mathrm{~nm}[40])$, poly(3,6-di(carbazol-9-yl)- $N$-(4-nitrophenyl)carbazole) $\left(\Delta T_{\max }=52 \%\right.$ at $710 \mathrm{~nm}$ [29]), and poly $\left(4,4^{\prime}\right.$-bis( $N$-carbazolyl)-1,1'-biphenyl) $\left(\Delta T_{\max }=44.1 \%\right.$ at $\left.800 \mathrm{~nm}\right)$ [41].

Table 3. Optical and electrochemical properties investigated at the selected applied wavelength for PtCz film and ECDs.

\begin{tabular}{|c|c|c|c|c|c|c|c|c|}
\hline PtCz film and ECDs & $\mathbf{N}$ & $T_{\mathrm{ox}}(\%)$ & $T_{\text {red }}(\%)$ & $\Delta T(\%)$ & $\Delta \mathrm{OD}$ & $\eta\left(\mathrm{cm}^{2} \cdot \mathrm{c}^{-1}\right)$ & $\tau_{\mathrm{c}} / \mathrm{s}$ & $\tau_{\mathrm{b}} / \mathrm{s}$ \\
\hline $\mathrm{PtCz}(760 \mathrm{~nm})^{\mathrm{a}}$ & 3 & 33.0 & 63.5 & 30.5 & -0.28 & 54.8 & 5.5 & 5.0 \\
\hline PtCz/PEDOT & 3 & 10.4 & 34.4 & 24.0 & -0.52 & 234.9 & 0.6 & 1.0 \\
\hline$(600 \mathrm{~nm})^{\mathrm{a}}$ & 50 & 10.8 & 33.0 & 22.2 & -0.49 & 256.5 & 0.2 & 0.2 \\
\hline Ptz/PProDOT-Me 2 & 3 & 11.6 & 47.6 & 36.0 & -0.61 & 248.4 & 0.2 & 0.6 \\
\hline$(572 \mathrm{~nm})^{\mathrm{a}}$ & 50 & 12.0 & 47.0 & 35.0 & -0.59 & 343.4 & 0.2 & 0.2 \\
\hline $\mathrm{PtCz}_{\text {/PProDOT-Et }}$ & 3 & 9.3 & 37.3 & 28.0 & -0.60 & 336.8 & 0.4 & 0.3 \\
\hline$(591 \mathrm{~nm})^{\mathrm{a}}$ & 50 & 9.8 & 36.4 & 26.6 & -0.57 & 330.7 & 0.1 & 0.1 \\
\hline
\end{tabular}

a The selected applied wavelength for PtCz film and ECDs. 
Table 4. Optical contrasts and coloration efficiencies of carbazole-based polymer films.

\begin{tabular}{cccc}
\hline Carbazole-based polymer films & $\Delta \boldsymbol{T}_{\max }(\mathbf{\%})$ & $\left.\eta \mathbf{( c m}^{\mathbf{2}} \cdot \mathbf{C}^{-\mathbf{1}}\right)$ & Ref. \\
\hline poly(9H-carbazol-9-ylpyrene) & $29(460 \mathrm{~nm})$ & - & {$[37]$} \\
poly(1,3-bis(carbazol-9-yl)benzene) & $18.6(1050 \mathrm{~nm})$ & 180.3 & {$[38]$} \\
poly(ethyl-4-(3,6-di(thiophen-2-yl)-9H-carbazole-9-yl)-benzoate) & $36(1100 \mathrm{~nm})$ & - & {$[39]$} \\
poly(2,5-bis(9-methyl-9H-carbazol-3-yl)-1,3,4-oxadiazole) & $75(660 \mathrm{~nm})$ & - & {$[40]$} \\
poly(3,6-di(carbazol-9-yl)- $N$-(4-nitrophenyl)-carbazole) & $52(710 \mathrm{~nm})$ & 35 & {$[29]$} \\
poly(4,4'-bis(N-carbazolyl)-1,1'-biphenyl) & $44.1(800 \mathrm{~nm})$ & 98 & {$[41]$} \\
PtCz & $30.5(760 \mathrm{~nm})$ & 54.8 & This work \\
\hline
\end{tabular}

The coloration efficiency $(\eta)$ of electrochromic materials can be estimated using the following equation [42]:

$$
\eta=\frac{\Delta \mathrm{OD}}{Q_{\mathrm{d}}}
$$

where $Q_{\mathrm{d}}$ is the charge density (injected/ejected charges per unit sample area). The $\eta$ value of PtCz film is $54.8 \mathrm{~cm}^{2} \cdot \mathrm{C}^{-1}$ at $760 \mathrm{~nm}$ in $0.2 \mathrm{M} \mathrm{LiClO}_{4} / \mathrm{ACN} / \mathrm{DCM}$ (ACN/DCM = 1:3, by volume) solution. The $\eta$ of $\mathrm{PtCz}$ film is larger than that reported for poly(3,6-di(carbazol-9-yl)- $N$-(4-nitrophenyl)carbazole) ( $\eta=35 \mathrm{~cm}^{2} \cdot \mathrm{C}^{-1}$ [29]). However, the $\Delta T_{\max }$ of $\mathrm{PtCz}$ film is smaller than those reported for poly $\left(4,4^{\prime}\right.$-bis( $N$-carbazolyl)-1,1'-biphenyl $\left(\eta=98 \mathrm{~cm}^{2} \cdot \mathrm{C}^{-1}\right.$ [41]) and poly(1,3-bis(carbazol-9-yl)benzene) $\left(\eta=180.3 \mathrm{~cm}^{2} \cdot \mathrm{C}^{-1}[38]\right)$.

\subsection{Spectroelectrochemistry of PtCz/PEDOT, PtCz/PProDOT-Me ${ }_{2}$, and PtCz/PProDOT-Et $t_{2}$ ECDs}

Figure 7 shows the UV-Visible spectra of PtCz/PEDOT, PtCz/PProDOT-Me 2 , and PtCz/PProDOT-Et ${ }_{2}$ ECDs at various voltages. At $0.0 \mathrm{~V}$, the PtCz/PEDOT, PtCz/PProDOT-Me 2 , and PtCz/PProDOT-Et ${ }_{2}$ ECDs show $\pi-\pi^{*}$ transition peaks of $\mathrm{PtC} z$ film at around $360 \mathrm{~nm}$.
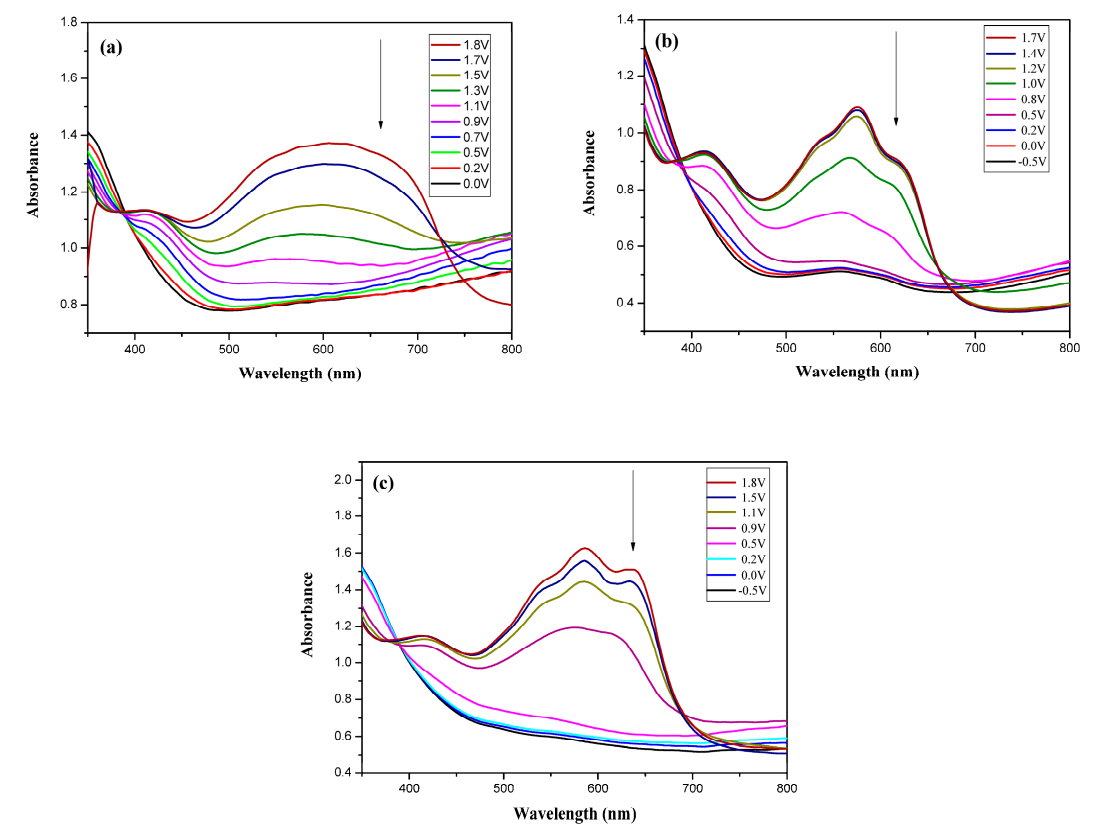

Figure 7. UV-visible spectra of (a) PtCz/PEDOT (b) PtCz/PProDOT-Me ${ }_{2}$, and (c) PtCz/PProDOT-Et 2 ECDs.

Upon increasing the potential gradually, the $\pi-\pi^{*}$ transition peak of $\mathrm{PtC} z$ film diminishes and new absorption band at around 580-650 nm emerges. At 1.7-1.8 V, PEDOT, PProDOT-Me $\mathrm{H}_{2}$ and PProDOT-Et ${ }_{2}$ films exhibit distinct absorption band at around 500-700 nm, and PtCz/PEDOT, $\mathrm{PtCz} /$ PProDOT-Me ${ }_{2}$, and PtCz/PProDOT-Et ${ }_{2}$ ECDs became dark blue at 1.7-1.8 V. The electrochromic photographs, colorimetric values $\left(L^{*}, a^{*}\right.$, and $\left.b^{*}\right)$, CIE chromaticity values $(x, y)$, and CIE chromaticity diagram of the $\mathrm{PtCz} / \mathrm{PProDOT}-\mathrm{Me}_{2}$ ECD at various potentials are summarized in Table 5. 
Table 5. Electrochromic photographs, colorimetric values $\left(L^{*}, a^{*}\right.$, and $\left.b^{*}\right)$, CIE chromaticity values $(x, y)$, and CIE chromaticity diagram of the PtCz/PProDOT-Me ${ }_{2}$ ECD at various applied potentials.

\begin{tabular}{|c|c|c|c|c|c|c|c|c|}
\hline ECD & Potential (V) & Photographs & $L^{*}$ & $a^{*}$ & $b^{*}$ & $x$ & $y$ & Diagram \\
\hline \multirow{5}{*}{$\begin{array}{c}\mathrm{PtCz} / \\
\text { PProDOT-Me }\end{array}$} & -0.8 & & 85.06 & -1.40 & 26.92 & 0.472 & 0.434 & \\
\hline & 0.0 & & 80.27 & -0.28 & 19.04 & 0.468 & 0.427 & \\
\hline & 0.8 & & 61.82 & 2.72 & -8.38 & 0.441 & 0.392 & \\
\hline & 1.2 & & 56.30 & 4.46 & -17.66 & 0.428 & 0.374 & \\
\hline & 1.5 & & 54.18 & 5.26 & -21.30 & 0.423 & 0.366 & \\
\hline
\end{tabular}

Figure 8 shows the transmittance-time profiles of $\mathrm{PtCz} / \mathrm{PEDOT}, \mathrm{PtCz} / \mathrm{PProDOT}-\mathrm{Me}_{2}$, and $\mathrm{PtCz} /$ PProDOT-Et $t_{2}$ ECDs by repeating potentials between 0.0 and $1.8 \mathrm{~V}$ with a time interval of $10 \mathrm{~s}$. The $\tau_{\mathrm{c}}$ and $\tau_{\mathrm{b}}$ estimated at various cycles for PtCz/PEDOT, PtCz/PProDOT-Me $\mathrm{e}_{2}$, and PtCz/PProDOT-Et $t_{2}$ ECDs are listed in Table 3. The $\tau_{\mathrm{c}}$ and $\tau_{\mathrm{b}}$ of PtCz/PEDOT ECD at $600 \mathrm{~nm}$ were 0.2 and $0.2 \mathrm{~s}$, respectively, at the 50th cycle. Under similar conditions, the $\tau_{\mathrm{c}}$ values of $\mathrm{PtCz} /$ PProDOT-Me $\mathrm{M}_{2}$ ECD at $572 \mathrm{~nm}$ and PtCz/PProDOT-Et $\mathrm{E}_{2}$ ECD at $591 \mathrm{~nm}$ were 0.2 and $0.1 \mathrm{~s}$ at the 50th cycle, respectively, and the corresponding $\tau_{\mathrm{b}}$ values were 0.2 and $0.1 \mathrm{~s}$ at the 50th cycle, respectively, indicating that PtCz/PEDOT, PtCz/PProDOT-Me ${ }_{2}$, and PtCz/PProDOT-Et ${ }_{2}$ ECDs showed fast switching speed when PtCz, PEDOT, PProDOT-Me ${ }_{2}$, and PProDOT-Et ${ }_{2}$ are employed as electrochromic layers. The $\tau_{\mathrm{c}}$ and $\tau_{\mathrm{b}}$ values of PtCz/PEDOT ECD were 0.6 and $1.0 \mathrm{~s}$, respectively, at the third cycle, and 0.2 and $0.2 \mathrm{~s}$, respectively, at the 50th cycle, indicating that switching time shortened with the number of switching cycles. Under similar conditions, $\mathrm{PtCz} / \mathrm{PProDOT}-\mathrm{Me}_{2}$ and $\mathrm{PtCz} /$ PProDOT-Et $\mathrm{E}_{2}$ ECDs showed fast switching speed at high switching cycles than those at low switching cycles.
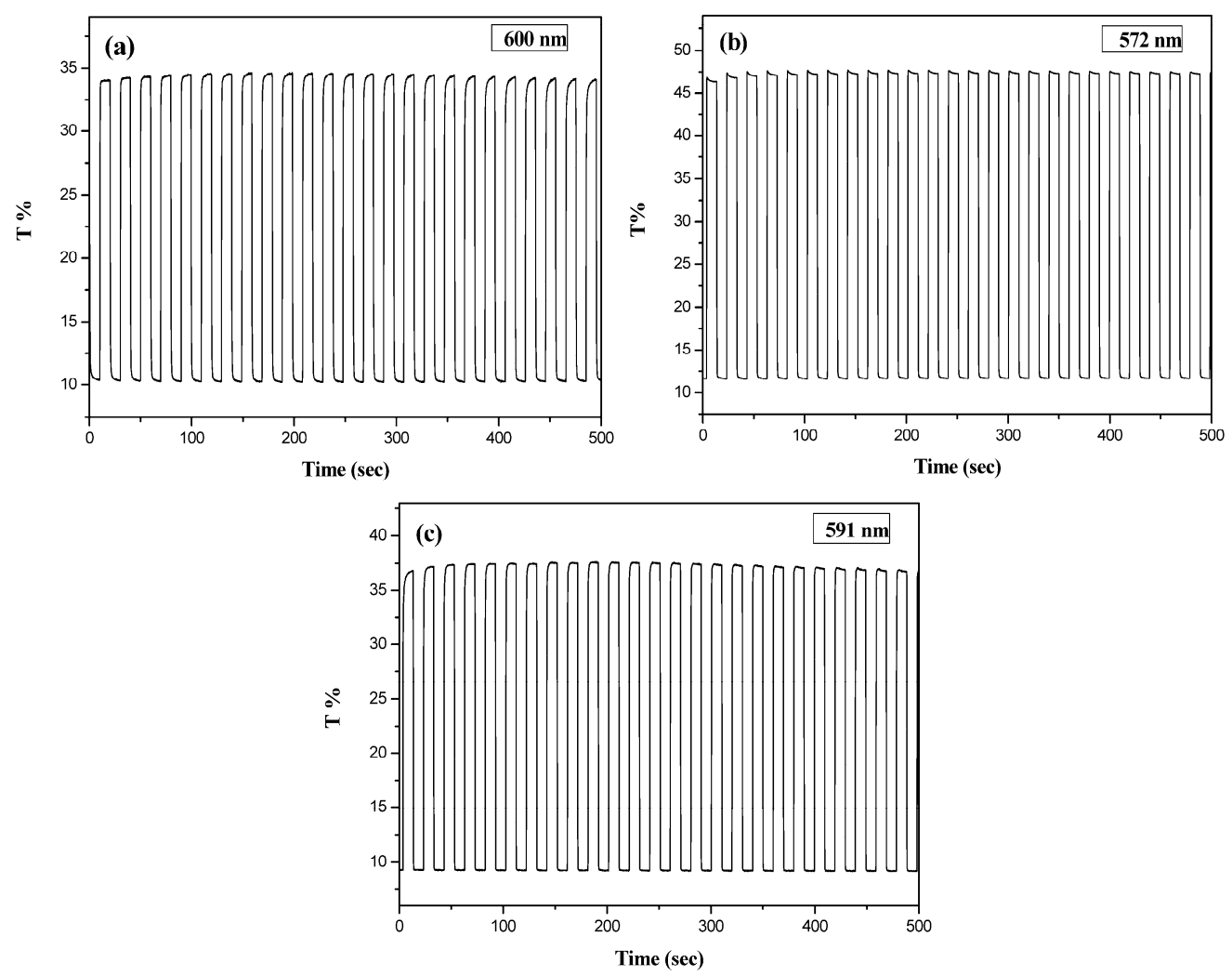

Figure 8. Optical contrast of (a) PtCz/PEDOT (b) PtCz/PProDOT-Me 2 , and (c) PtCz/PProDOT-Et 2 ECDs in an ACN/DCM (1:3, by volume) solution containing $0.2 \mathrm{M} \mathrm{LiClO}_{4}$ between $0.0 \mathrm{~V}$ and $1.8 \mathrm{~V}$ with a residence time of $10 \mathrm{~s}$. 
As summarized in Table 3, the $\Delta T$ values of PtCz/PEDOT, PtCz/PProDOT-Me 2 , and PtCz/PProDOT$\mathrm{Et}_{2}$ ECDs were $24.0,36.0$, and $28.0 \%$ at the 3 rd cycle, respectively. The $\Delta T$ of PtCz/PProDOT-Me 2 and $\mathrm{PtCz} / \mathrm{PProDOT}_{-} \mathrm{Et}_{2}$ ECDs were larger than that of PtCz/PEDOT, indicating PProDOT derivatives facilitated to increase the transmittance disparity when we employed PProDOT derivatives as cathodic layers in ECDs. PtCz/PProDOT-Me ${ }_{2}$ ECD shows the highest $\Delta T$ among these ECDs, the $\Delta T$ of $\mathrm{PtCz} / \mathrm{PProDOT}-\mathrm{Me}_{2} \mathrm{ECD}$ is higher than those reported for poly $\left(4,4^{\prime}-\right.$ di(N-carbazolyl)biphenyl)/PEDOT [43], poly(9H-carbazol-9-ylpyrene)/PEDOT [37], poly(3,6-bis(2(3,4-ethylenedioxy)thienyl)- $N$-methylcarbazole)/PEDOT [44], poly(carbazole-co-indole-6-carboxylic acid)/PProDOT- $\mathrm{Me}_{2}$ [45], poly(4,4'-di(N-carbazoyl)biphenyl-co-2,2'-bithiophene)/PEDOT [46] and poly(2,5-bis(9-methyl-9H-carbazol-3-yl)-1,3,4-oxadiazole)/PEDOT [40] ECDs (Table 6). However, PtCz/PProDOT-Me 2 ECD shows lower $\Delta T$ than that reported for poly $\left(4,4^{\prime}-\mathrm{di}(\mathrm{N}-\right.$ carbazoyl)biphenyl-co-4H-cyclopenta[2,1-b:3,4-b'] dithiophene)/PEDOT ECD [47].

Table 6. Optical contrast and coloration efficiencies of ECDs.

\begin{tabular}{|c|c|c|c|}
\hline ECD configuration & $\Delta T_{\max }(\%)$ & $\begin{array}{c}\eta_{\max } \\
\left(\mathrm{cm}^{2} \cdot \mathrm{C}^{-1}\right)\end{array}$ & Ref. \\
\hline poly $\left(4,4^{\prime}\right.$-di( $N$-carbazolyl)biphenyl $) /$ PEDOT & $19(550 \mathrm{~nm})$ & - & [43] \\
\hline poly(9H-carbazol-9-ylpyrene)/PEDOT & $23(623 \mathrm{~nm})$ & 290 & [37] \\
\hline poly(carbazole-co-indole-6-carboxylic acid)/PProDOT-Me 2 & $32(575 \mathrm{~nm})$ & 372.7 & [45] \\
\hline poly $\left(4,4^{\prime}\right.$-di( $N$-carbazoyl)biphenyl-co-2,2'-bithiophene $) /$ PEDOT & $28.6(700 \mathrm{~nm})$ & 234 & [46] \\
\hline poly $\left(4,4^{\prime}\right.$-di( $N$-carbazoyl)biphenyl-co- $4 H$-cyclopenta[2,1-b:3,4- $\left.b^{\prime}\right]$ dithiophene)/PEDOT & $39.8(628 \mathrm{~nm})$ & 319.98 & [47] \\
\hline
\end{tabular}

The $\Delta T$ values of PtCz/PEDOT ECD were 24.0 and $22.2 \%$ at the 3 rd and 50th cycles, respectively. The $\Delta T$ of PtCz/PEDOT ECD decreases $1.8 \%$ from the 3 rd to 50th cycles. Under similar conditions, the $\Delta T$ values of $\mathrm{PtCz} /$ PProDOT-Me $\mathrm{M}_{2}$ and PtCz/PProDOT-Et ${ }_{2}$ ECDs were 36.0 and $28.0 \%$ at the 3 rd cycle, respectively, and 35.0 and $26.6 \%$ at the 50th cycle, respectively. The $\Delta T$ values of $\mathrm{PtCz} /$ PProDOT-Me ${ }_{2}$ and PtCz/PProDOT-Et ${ }_{2}$ ECDs decrease 1.0 and $1.4 \%$ from the 3rd to 50th cycles, respectively. This result indicates that the incorporation of PProDOT-Me ${ }_{2}$ and PProDOT-Et $\mathrm{F}_{2}$ as cathodic polymers gives rise to better $\Delta T$ stability than that obtained using PEDOT as the cathodic polymer.

The $\eta$ value is high when $\eta$ of ECDs is larger than $300 \mathrm{~cm}^{2} \cdot \mathrm{C}^{-1}$. As summarized in Table 3 , the $\eta_{\max }$

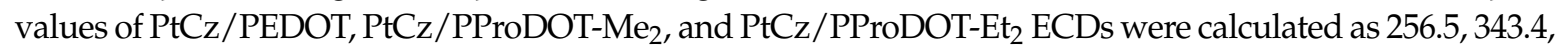
and $336.8 \mathrm{~cm}^{2} \cdot \mathrm{C}^{-1}$, respectively, the $\eta_{\max }$ value of $\mathrm{PtCz} / \mathrm{PProDOT}-\mathrm{Me}_{2}$ and $\mathrm{PtCz} / \mathrm{PProDOT}-\mathrm{Et}_{2} \mathrm{ECDs}_{\text {are }}$ larger than that of PtCz/PEDOT ECD, indicating that PProDOT derivatives-based cathodic polymer leads to higher $\eta$ than that of PEDOT-based cathodic polymer. As shown in Table 6, PtCz/PProDOT-Me 2 ECD shows higher $\eta_{\max }$ than those reported for poly(9H-carbazol-9-ylpyrene)/PEDOT [37], poly(4,4'-di(N-carbazoyl)biphenyl-co-4H-cyclopenta[2,1-b:3,4-b']dithiophene)/PEDOT [47], and poly(4,4'di(N-carbazoyl)biphenyl-co-2,2'-bithiophene)/PEDOT [46] ECDs. However, PtCz/PProDOT-Me 2 ECD shows lower $\eta_{\max }$ than that reported for poly(carbazole-co-indole-6-carboxylic acid)/PProDOT$\mathrm{Me}_{2}$ ECD [45].

\subsection{Open Circuit Memory of ECDs}

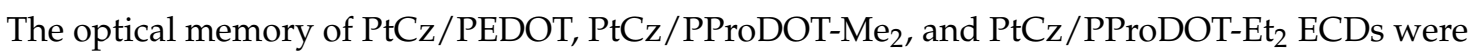
monitored at 600,572 , and $591 \mathrm{~nm}$, respectively, as a function of time at 0.0 and $1.8 \mathrm{~V}$ by applying the potential for $1 \mathrm{~s}$ at each $100 \mathrm{~s}$ time interval. As shown in Figure $9 \mathrm{a}-\mathrm{c}$, three ECDs show almost no change of transmittance in the bleached state, i.e., a durable memory effect. The transmittances of three ECDs in the colored state are less stable than in the bleached state, but the transmittance loss is less than 3\%. Both the bleached and colored states were highly stable, and the ECDs kept their color without loss, demonstrating PtCz/PEDOT, PtCz/PProDOT-Me ${ }_{2}$, and PtCz/PProDOT-Et ${ }_{2}$ ECDs reveal satisfied open circuit memory. 

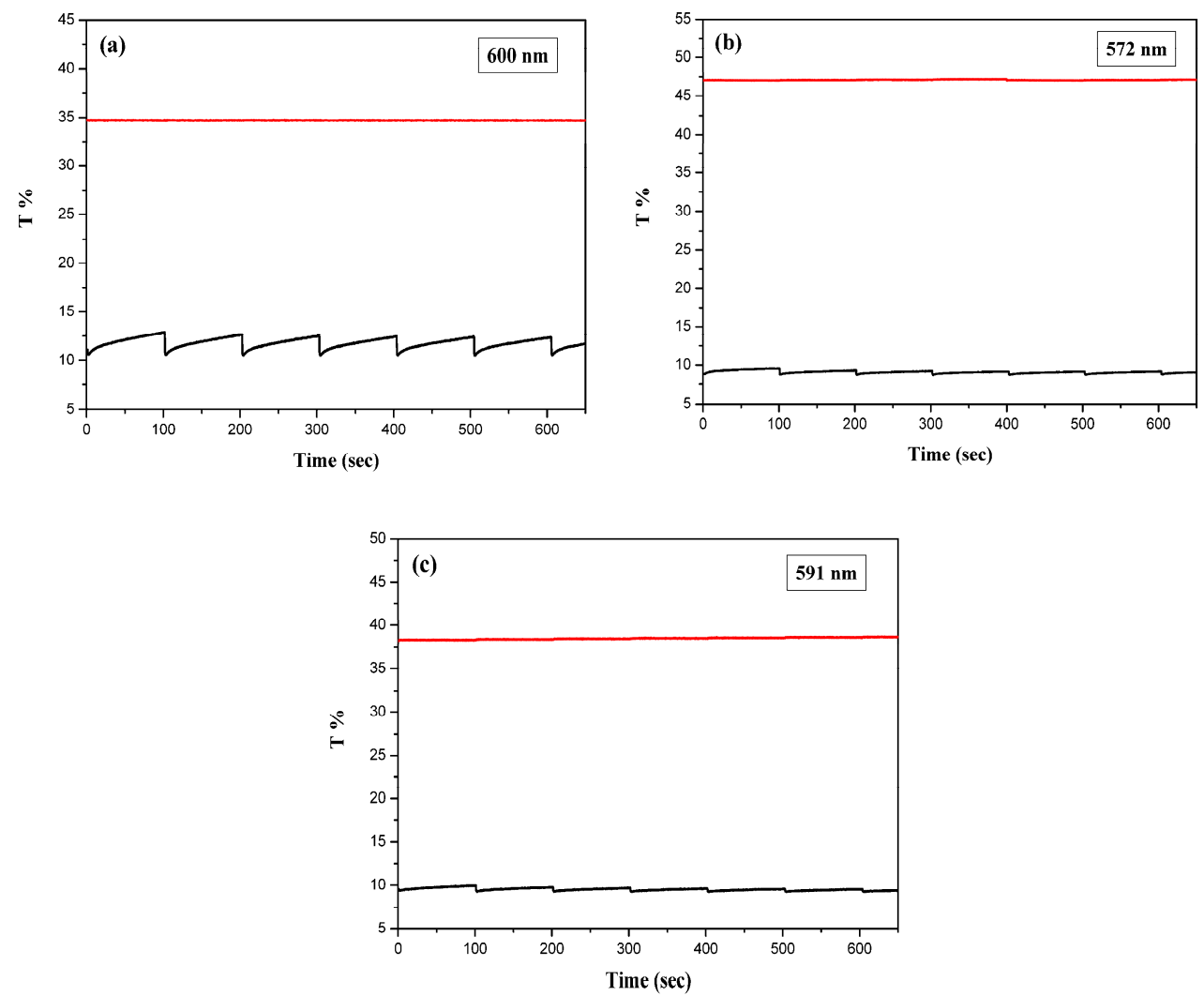

Figure 9. Open circuit stability of (a) PtCz/PEDOT (b) PtCz/PProDOT-Me 2 , and (c) PtCz/PProDOT-Et ${ }_{2}$ ECDs at $0.0 \mathrm{~V}$ and $1.8 \mathrm{~V}$. The working electrode is $\mathrm{PtCz}$ film-coated ITO glass substrate.

\subsection{Long-Term Stability of ECDs}

The stability of long-term switching between redox states is important for ECDs' applications [48,49]. The long-term switching ability between redox states of PtCz/PEDOT, PtCz/PProDOT-Me ${ }_{2}$, and $\mathrm{PtCz} /$ PProDOT-Et $_{2}$ ECDs were examined using $\mathrm{CV}$ at potentials between 0.0 and $1.5 \mathrm{~V}$ with a scan rate of $500 \mathrm{mV} \cdot \mathrm{s}^{-1}$ (Figure 10). From the observation of switching between bleaching and coloring states of the ECDs, $93 \%, 92 \%$, and $93 \%$ of their electrical activities are retained after 500 cycles for PtCz/PEDOT, PtCz/PProDOT-Me , $_{2}$ and PtCz/PProDOT-Et $t_{2}$ ECDs, respectively, and 87\%, $87 \%$, and $87 \%$ of their electrical activities are retained after 1000 cycles for PtCz/PEDOT, $\mathrm{PtCz} / \mathrm{PProDOT}-\mathrm{Me}_{2}$, and $\mathrm{PtCz} /$ PProDOT-Et ${ }_{2}$ ECDs, respectively, the electrical activities of $\mathrm{PtCz} / \mathrm{PEDOT}, \mathrm{PtCz} / \mathrm{PProDOT}-\mathrm{Me}_{2}$, and $\mathrm{PtCz} /$ PProDOT $\mathrm{Et}_{2} \mathrm{ECDs}_{\text {at }}$ 500th cycle are larger than those reported for $\mathrm{P}(\mathrm{BTN}-\mathrm{co}-\mathrm{BT}) / \mathrm{PEDOT} \mathrm{ECD}$ (stability $=79 \%$ at 500th cycle) [50] and PBTBE $/$ PEDOT ECD (stability $=80.2 \%$ at 500th cycle) [51], indicating they are good candidates for electrochromic applications. 

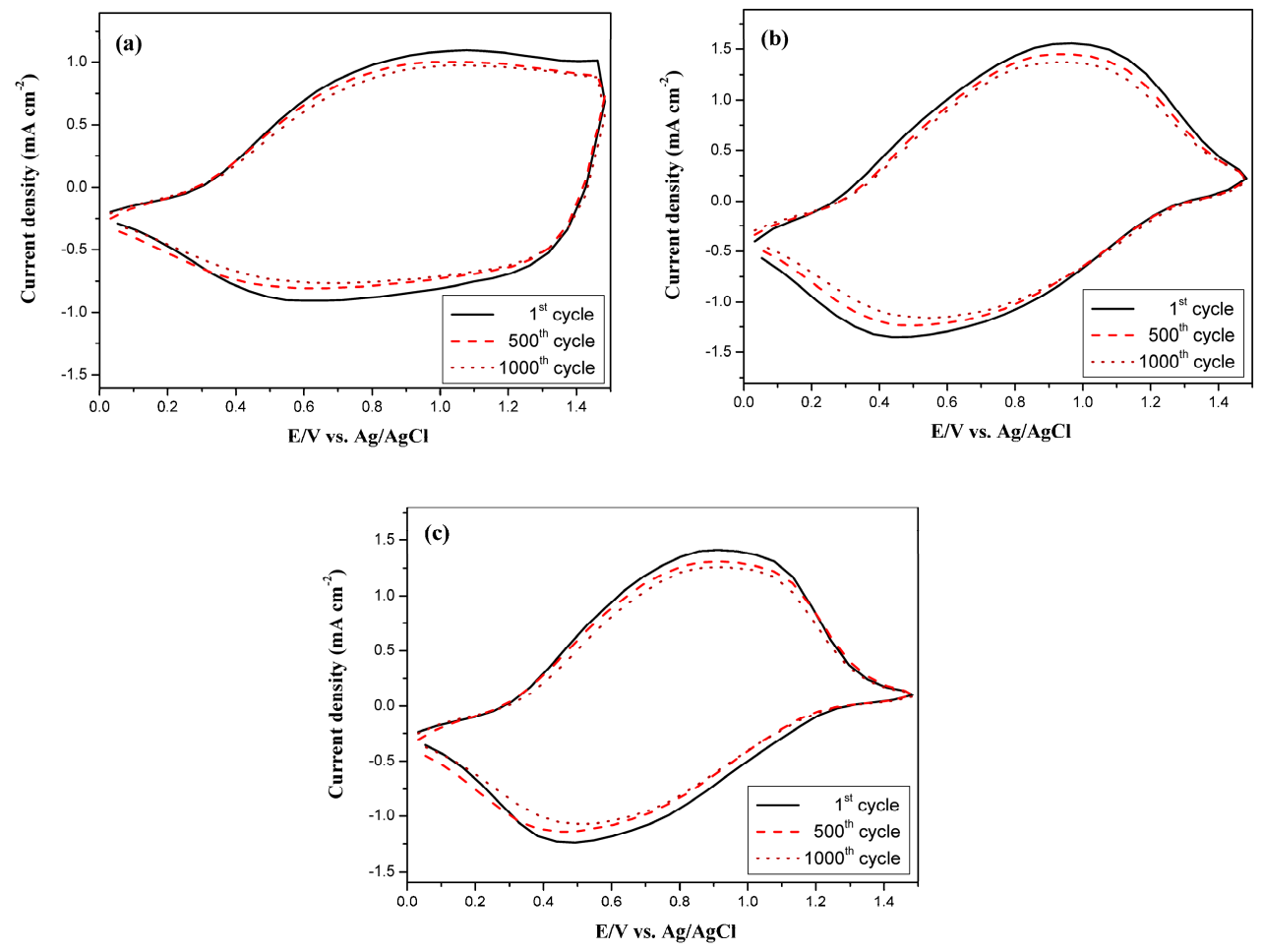

Figure 10. Cyclic voltammograms of (a) PtCz/PEDOT; (b) PtCz/PProDOT-Me ; $_{2}$ and (c) PtCz/PProDOT$\mathrm{Et}_{2}$ ECDs as a function of repeated with a scan rate of $500 \mathrm{mV} \cdot \mathrm{s}^{-1}$ between 1 and 1000 cycles. The working electrode is PtCz film-coated ITO glass substrate.

\section{Conclusions}

A carbazole-based monomer $(\mathrm{tCz})$ was synthesized, and its corresponding homopolymer $(\mathrm{PtCz})$ was prepared using electrochemical polymerization. The electrochemical processes of $\mathrm{PtCz}$ film are reversible, and the $\mathrm{PtCz}$ film shows four color variations (light yellow, earthy yellow, grey, and dark grey) from an undoped state to a doped state. Three ECDs based on PtCz as anodic polymer and PEDOT, PProDOT-Me ${ }_{2}$, and PProDOT-Et $t_{2}$ as the cathodic polymers were constructed, and the spectroelectrochemical properties of ECDs were characterized. The colors of constructed $\mathrm{PtCz} / \mathrm{PProDOT}-\mathrm{Me}_{2}$ ECD switched from yellowish-grey, light grey, purple, and dark blue upon the application of potential between -0.8 and $+1.5 \mathrm{~V}$. Electrochromic switching studies showed that the $\Delta T_{\max }$ values of PtCz/PEDOT, PtCz/PProDOT-Me $e_{2}$, and PtCz/PProDOT-Et $\mathrm{E}_{2} \mathrm{ECDs}_{\text {were }}$ $24.0 \%, 36.0 \%$, and $28.0 \%$, respectively, and the $\eta_{\max }$ values of PtCz/PEDOT, PtCz/PProDOT-Me ${ }_{2}$, and $\mathrm{PtCz} /$ PProDOT-Et $t_{2}$ ECDs were calculated as $256.5,343.4$, and $336.8 \mathrm{~cm}^{2} \cdot \mathrm{C}^{-1}$, respectively. Moreover, PtCz/PEDOT, PtCz/PProDOT-Me ${ }_{2}$, and PtCz/PProDOT-Et $\mathrm{E}_{2}$ ECDs reveal satisfied open circuit memory and long-term switching ability between redox states. The results show that the $\mathrm{PtCz}$ film is a potential anodic material for electrochromic applications in rear-view mirrors and motorcycle helmet-visors.

Acknowledgments: The authors would like to thank the Ministry of Science and Technology (MOST) of the Republic of China for financially supporting this project.

Author Contributions: Chung-Wen Kuo conceived the research topic; Po-Ying Lee and Tzi-yi Wu carried out the experiments; and Po-Ying Lee, Chung-Wen Kuo, Jeng-Kuei Chang, Yuan-Chung Lin, Tzi-Yi Wu, and Tsung-Han Ho analyzed the electrochromic properties.

Conflicts of Interest: The authors declare no conflict of interest. 


\section{References}

1. Mao, L.; Li, Y.; Chi, C.Y.; Chan, H.S.O.; Wu, J.S. Conjugated polyfluorene imidazolium ionic liquids intercalated reduced graphene oxide for high performance supercapacitor electrodes. Nano Energy 2014, 6, 119-128. [CrossRef]

2. Fu, W.C.; Hsieh, Y.T.; Wu, T.Y.; Sun, I.W. Electrochemical preparation of porous poly(3,4-ethylenedioxythiophene) electrodes from room temperature ionic liquids for supercapacitors. J. Electrochem. Soc. 2016, 163, G61-G68. [CrossRef]

3. Wu, T.Y.; Kuo, C.W.; Chen, Y.L.; Chang, J.K. Copolymers based on indole-6-carboxylic acid and 3,4-ethylenedioxythiophene as platinum catalyst support for methanol oxidation. Catalysts 2015, 5, 1657-1672. [CrossRef]

4. Wu, T.Y.; Chen, B.K.; Chang, J.K.; Chen, P.R.; Kuo, C.W. Nanostructured poly(aniline-co-metanilic acid) as platinum catalyst support for electro-oxidation of methanol. Int. J. Hydrogen Energy 2015, 40, 2631-2640. [CrossRef]

5. Kuo, C.W.; Kuo, Z.Y.; Jow, J.J.; Wu, T.Y.; Chen, J.Y.; Zhu, X.X. Enhanced electrocatalytic performance for methanol oxidation via insertion of ruthenium oxide particles into $\mathrm{Pt}$ and polyaniline-poly(acrylic acid-co-maleic acid) composite electrode. Int. J. Electrochem. Sci. 2012, 7, 4974-4987. [CrossRef]

6. Smela, E. Conjugated polymer actuators for biomedical applications. Adv. Mater. 2003, 15, 481-494. [CrossRef]

7. Wu, T.Y.; Lee, N.C.; Chen, Y. Synthesis and characterization of new poly( $p$-phenylenevinylene) derivative containing 5,5'-diphenyl-2,2-p-(2,5-bis-hexyloxyphenylene)-bis-1,3,4-oxadiazole and distyrylbenzene moieties. Synth. Met. 2003, 139, 263-269. [CrossRef]

8. Al-Asbahi, B.A.; Haji Jumali, M.H.; AlSalhi, M.S. Enhanced optoelectronic properties of PFO/fluorol 7GA hybrid light emitting diodes via additions of $\mathrm{TiO}_{2}$ nanoparticles. Polymers 2016, 8, 334. [CrossRef]

9. Wu, T.Y.; Chen, Y. Synthesis, optical and electrochemical properties of novel copolymers containing alternate 2,3-quinoxaline and hole-transporting units. J. Polym. Sci. Part A Polym. Chem. 2002, 40, 4570-4580. [CrossRef]

10. Hsiao, S.H.; Chiu, Y.T. Electrosynthesis and electrochromic properties of poly(amide-triarylamine)s containing triptycene units. RSC Adv. 2015, 5, 90941-90951. [CrossRef]

11. Triantou, D.; Soulis, S.; Asaftei, C.S.; Janietz, S. Effect of the acceptor moiety on the electrochemical and electrochromic properties of donor-acceptor-donor polymer films. Int. J. Electrochem. Sci. 2015, 10, 3458-3477.

12. Hsiao, S.H.; Teng, C.Y.; Kung, Y.R. Synthesis and characterization of novel electrochromic poly(amide-imide)s with $N, N^{\prime}$-di(4-methoxyphenyl)-N, $N^{\prime}$-diphenyl-p-phenylenediamine units. RSC Adv. 2015, 5, 93591-93606. [CrossRef]

13. Lam, K.T.; Hsiao, Y.J.; Ji, L.W.; Fang, T.H.; Shih, W.S.; Lin, J.N. Characteristics of polymer-fullerene solar cells with ZnS nanoparticles. Int. J. Electrochem. Sci. 2015, 10, 3914-3922.

14. Wu, T.Y.; Sheu, R.B.; Chen, Y. Synthesis and optically acid-sensory and electrochemical properties of novel polyoxadiazole derivatives. Macromolecules 2004, 37, 725-733. [CrossRef]

15. Choi, S.; Kim, Y. Gold nanoparticle-based fluorescent "turn-on" sensing system for the selective detection of mercury ions in aqueous solution. RSC Adv. 2015, 5, 95268-95272. [CrossRef]

16. Wu, T.Y.; Chen, Y. Poly(phenylene vinylene)-based copolymers containing 3,7-phenothiazylene and 2,6-pyridylene chromophores: Fluorescence sensors for acids, metal ions, and oxidation. J. Polym. Sci. Part A Polym. Chem. 2004, 42, 1272-1284. [CrossRef]

17. Wu, T.Y.; Chen, Y. Synthesis and characterization of novel luminescent polymers with alternate phenothiazine and divinylbenzene units. J. Polym. Sci. Part A Polym. Chem. 2002, 40, 4452-4462. [CrossRef]

18. Hsiao, S.H.; Hsueh, J.C. Electrochemical synthesis and electrochromic properties of new conjugated polycarbazoles from di(carbazol-9-yl)-substituted triphenylamine and $N$-phenylcarbazole derivatives. J. Electroanal. Chem. 2015, 758, 100-110. [CrossRef]

19. Hsiao, S.H.; Wu, L.C. Fluorescent and electrochromic polymers from 2,8-di(carbazol-9-yl)dibenzothiophene and its $S, S$-dioxide derivative. Dye Pigments 2016, 134, 51-63. [CrossRef]

20. Liu, J.; Mi, S.; Xu, Z.; Wu, J.; Zheng, J.; Xu, C. Solution-processable thiophene-based electrochromic polymers bearing trifluoromethyl rather than long side chains. Org. Electron. 2016, 37, 169-177. [CrossRef] 
21. Ahmad, S.; Gursoy, S.S.; Kazim, S.; Uygun, A. Growth of $N$-substituted polypyrrole layers in ionic liquids: Synthesis and its electrochromic properties. Sol. Energy Mater. Sol. Cells 2012, 99, 95-100. [CrossRef]

22. Hacioglu, S.O.; Yiğit, D.; Ermis, E.; Soylemez, S.; Güllü, M.; Toppare, L. Syntheses and electrochemical characterization of low oxidation potential nitrogen analogs of pedot as electrochromic materials. J. Electrochem. Soc. 2016, 163, E293-E299. [CrossRef]

23. Wu, T.Y.; Chen, P.R.; Chen, H.R.; Kuo, C.W. Preparation of Pt/poly(aniline-co-orthanilic acid)s nanocomposites and their applications for electrocatalytic oxidation of methanol. J. Taiwan Inst. Chem. Eng. 2016, 58, 458-466. [CrossRef]

24. Soyleyici, S.; Karakus, M.; Ak, M. Transparent-blue colored dual type electrochromic device: Switchable glass application of conducting organic-inorganic hybrid carbazole polymer. J. Electrochem. Soc. 2016, 163, H679-H683. [CrossRef]

25. Cansu-Ergun, E.G.; Onal, A.M.; Cihaner, A. Propylenedioxy and benzimidazole based electrochromic polymers. J. Electrochem. Soc. 2016, 163, G53-G60. [CrossRef]

26. Sassi, M.; Salamone, M.M.; Ruffo, R.; Patriarca, G.E.; Mari, C.M.; Pagani, G.A.; Posset, U.; Beverina, L. Organic electrochromic polymers: State-of-the-art neutral tint multichromophoric polymers for high-contrast see-through electrochromic devices. Adv. Funct. Mater. 2016, 26, 5240-5246. [CrossRef]

27. Karon, K.; Lapkowski, M.; Dabuliene, A.; Tomkeviciene, A.; Kostiv, N.; Grazulevicius, J.V. Spectroelectrochemical characterization of conducting polymers from star-shaped carbazole-triphenylamine compounds. Electrochim. Acta 2015, 154, 119-127. [CrossRef]

28. Welsh, D.M.; Kumar, A.; Meijer, E.W.; Reynolds, J.R. Enhanced contrast ratio and rapid switching in electrochromics based on poly(3,4-propylenedioxythiophene) derivatives. Adv. Mater. 1999, 11, 1379-1382. [CrossRef]

29. Hsiao, S.H.; Lin, S.W. Electrochemical synthesis of electrochromic polycarbazole films from N-phenyl3,6-bis(N-carbazolyl)carbazoles. Polym. Chem. 2016, 7, 198-211. [CrossRef]

30. Wu, T.Y.; Su, Y.S. Electrochemical synthesis and characterization of 1,4-benzodioxan-based electrochromic polymer and its application in electrochromic devices. J. Electrochem. Soc. 2015, 162, G103-G112. [CrossRef]

31. Chang, K.H.; Wang, H.P.; Wu, T.Y.; Sun, I.W. Optical and electrochromic characterizations of four 2,5-dithienylpyrrole-based conducting polymer films. Electrochim. Acta 2014, 119, 225-235. [CrossRef]

32. Wu, T.Y.; Li, W.B.; Kuo, C.W.; Chou, C.F.; Liao, J.W.; Chen, H.R.; Tseng, C.G. Study of poly(methyl methacrylate)-based gel electrolyte for electrochromic device. Int. J. Electrochem. Sci. 2013, 8, 10720-10732.

33. Wu, T.Y.; Chung, H.H. Applications of tris(4-(thiophen-2-yl)phenyl)amine- and dithienylpyrrole-based conjugated copolymers in high-contrast electrochromic devices. Polymers 2016, 8, 206. [CrossRef]

34. Vernardou, D.; Paterakis, P.; Drosos, H.; Spanakis, E.; Povey, I.M.; Pemble, M.E.; Koudoumas, E.; Katsarakis, N. A study of the electrochemical performance of vanadium oxide thin films grown by atmospheric pressure chemical vapour deposition. Sol. Energy Mater. Sol. Cells 2011, 95, 2842-2847. [CrossRef]

35. Vernardou, D.; Louloudakis, D.; Spanakis, E.; Katsarakis, N.; Koudoumas, E. Electrochemical properties of vanadium oxide coatings grown by hydrothermal synthesis on FTO substrates. New J. Chem. 2014, 38, 1959-1964. [CrossRef]

36. Louloudakis, D.; Vernardou, D.; Spanakis, E.; Katsarakis, N.; Koudoumas, E. Electrochemical properties of vanadium oxide coatings grown by APCVD on glass substrates. Surf. Coat. Technol. 2013, 230, 186-189. [CrossRef]

37. Wang, B.; Zhao, J.; Xiao, J.; Cui, C.; Liu, R. Synthesis and electropolymerization of 9H-carbazol-9-ylpyrene and its electrochromic properties and electrochromic device application. Int. J. Electrochem. Sci. 2012, 7, 2781-2795.

38. Kuo, C.-W.; Wu, T.-L.; Lin, Y.-C.; Chang, J.-K.; Chen, H.-R.; Wu, T.-Y. Copolymers based on 1,3-bis(carbazol-9-yl)benzene and three 3,4-ethylenedioxythiophene derivatives as potential anodically coloring copolymers in high-contrast electrochromic devices. Polymers 2016, 8, 368. [CrossRef]

39. Hu, B.; Lv, X.; Sun, J.; Bian, G.; Ouyang, M.; Fu, Z.; Wang, P.; Zhang, C. Effects on the electrochemical and electrochromic properties of 3,6 linked polycarbazole derivative by the introduction of different acceptor groups and copolymerization. Org. Electron. 2013, 14, 1521-1530. [CrossRef] 
40. Udum, Y.A.; Gündoğdu Hizlıateş, C.; Ergün, Y.; Toppare, L. Electrosynthesis and characterization of an electrochromic material containing biscarbazole-oxadiazole units and its application in an electrochromic device. Thin Solid Films 2015, 595, 61-67. [CrossRef]

41. Kuo, C.W.; Wu, T.Y.; Huang, M.W. Electrochromic characterizations of copolymers based on 4,4'-bis(N-carbazolyl)-1,1'-biphenyl and indole-6-carboxylic acid and their applications in electrochromic devices. J. Taiwan Inst. Chem. Eng. 2016, 68, 481-488. [CrossRef]

42. Kuo, C.W.; Chen, B.K.; Li, W.B.; Tseng, L.Y.; Wu, T.Y.; Tseng, C.G.; Chen, H.R.; Huang, Y.C. Effects of supporting electrolytes on spectroelectrochemical and electrochromic properties of polyaniline-poly(styrene sulfonic acid) and poly(ethylenedioxythiophene)-poly(styrene sulfonic acid)-based electrochromic device. J. Chin. Chem. Soc. 2014, 61, 563-570. [CrossRef]

43. Koyuncu, S.; Gultekin, B.; Zafer, C.; Bilgili, H.; Can, M.; Demic, S.; Kaya, I.; Icli, S. Electrochemical and optical properties of biphenyl bridged-dicarbazole oligomer films: Electropolymerization and electrochromism. Electrochim. Acta 2009, 54, 5694-5702. [CrossRef]

44. Seshadri, V.; Padilla, J.; Bircan, H.; Radmard, B.; Draper, R.; Wood, M.; Otero, T.F.; Sotzing, G.A. Optimization, preparation, and electrical short evaluation for $30 \mathrm{~cm}^{2}$ active area dual conjugated polymer electrochromic windows. Org. Electron. 2007, 8, 367-381. [CrossRef]

45. Kuo, C.W.; Hsieh, T.H.; Hsieh, C.K.; Liao, J.W.; Wu, T.Y. Electrosynthesis and characterization of four electrochromic polymers based on carbazole and indole-6-carboxylic acid and their applications in high-contrast electrochromic devices. J. Electrochem. Soc. 2014, 161, D782-D790. [CrossRef]

46. Wang, B.; Zhao, J.; Liu, R.; Liu, J.; He, Q. Electrosyntheses, characterizations and electrochromic properties of a copolymer based on 4,4'-di(N-carbazoyl)biphenyl and 2,2'-bithiophene. Sol. Energy Mater. Sol. Cells 2011, 95, 1867-1874. [CrossRef]

47. Chen, S.; Gao, Q.; Zhao, J.; Cui, C.; Yang, W.; Zhang, X. Electrosyntheses, characterizations and electrochromic properties of a novel copolymer of 4,4'-di(N-carbazoyl)biphenyl with $4 H$-cyclopenta[2,1-b:3,4- $\left.b^{\prime}\right]$ dithiophene. Int. J. Electrochem. Sci. 2012, 7, 5256-5272.

48. Wu, T.Y.; Liao, J.W.; Chen, C.Y. Electrochemical synthesis, characterization and electrochromic properties of indan and 1,3-benzodioxole-based poly(2,5-dithienylpyrrole) derivatives. Electrochim. Acta 2014, 150, 245-262. [CrossRef]

49. Soganci, T.; Soyleyici, H.C.; Ak, M.; Cetisli, H. An amide substituted dithienylpyrrole based copolymer: Its electrochromic properties physical and analytical electrochemistry, electrocatalysis, and photoelectrochemistry. J. Electrochem. Soc. 2016, 163, H59-H66. [CrossRef]

50. Cui, C.; Xu, C.; Xu, L.; Zhao, J.; Liu, R.; Liu, J.; He, Q.; Wang, H. Electrosynthesis and characterization of a multielectrochromic copolymer of 1,4-bis(2-thienyl)-naphthalene with 2,2'-bithiophene. Opt. Mater. 2011, 33, 1792-1799. [CrossRef]

51. Cui, C.; Xu, L.; Zhao, J.; He, Q.; Wang, B. Electrosynthesis and characterization of a new multielectrochromic copolymer of 1,4-bis(2-thienyl)benzene with 3,4-ethylenedioxythiophene. J. Appl. Polym. Sci. 2012, 125, 3591-3601. [CrossRef]

(C) 2017 by the authors. Licensee MDPI, Basel, Switzerland. This article is an open access article distributed under the terms and conditions of the Creative Commons Attribution (CC BY) license (http:// creativecommons.org/licenses/by/4.0/). 